\title{
Discursos sobre a leitura: entre a unidade e a pluralidade
}

\section{Claudia Lemos Vóvio*}

\section{Resumo}

Este artigo discorre sobre enfoques acerca da leitura que atravessam e constituem discursos correntes sobre essa prática social e seus significados, portanto influentes nos modos como se focalizam objetos e nas análises tecidas em pesquisas sobre letramentos (STREET, 1984; KLEIMAN, 1995; BARTON; HAMILTON; IVANIC 2000; GEE, 2000, 2004). A matriz epistemológica assumida compreende a leitura como prática cultural produzida nas/pelas relações entre grupos humanos, em tempos e espaços sociais específicos, sendo, portanto, variável. Como tal, é perpassada por fenômenos que trazem em seu bojo a necessidade da leitura como prática cultural desejável: o da legitimidade (de crenças coletivas que edificaram a leitura como prática necessária) e o da desigualdade, que diz respeito à distribuiçáo de oportunidades de acesso, à difusão de práticas, competências e objetos (LAHIRE, 2002, 2006). Abordar tais discursos correntes e os enfoques a eles correspondentes permite, por um lado, compreender em que bases os discursos da tradição e do cânone foram produzidos e converteram-se em divisores de águas capazes de distinguir grupos e pessoas, de definir o que conta, o que tem valor, de escalonar e classificar leitores e leituras e, de outro, organizar planos a partir dos quais se pode examinar as práticas de leitura, os sentidos e significados atribuídos a esse fazer e os artefatos culturais acessados pelos sujeitos envolvidos.

Palavras-chave: Letramento. Práticas de leitura. Formação leitora.

* Professora Adjunta da Universidade Federal de São Paulo, no curso de Pedagogia, e colaboradora do programa de Educaçáo de Jovens e Adultos da ONG Açáo Educativa. 


\section{Discursos sobre a leitura: entre a unidade e a pluralidade}

[...] embora a leitura em si pareça um ato solitário né... só você e o livro... eu vejo a leitura assim [...] um momento de diálogo[...] né. (Educadora de jovens e adultos, 2004).

Atualmente, nos discursos sobre a leitura, saltam aos olhos as diversas formas, antagônicas, convergentes, complementares e contrastivas de se referir ao mesmo objeto. Na multiplicidade e dispersáo dos discursos, em suas esferas de produção, circulação e consumo, tais modos de referir-se ganham formas e contornos distintos, gerando posiçóes, formas de valorá-lo e apreciá-lo com efeitos de sentido variados. ${ }^{1}$

A epígrafe deste artigo $^{2}$ é um exemplar dessa dinâmica. $\mathrm{O}$ excerto extraído de uma entrevista com uma educadora de jovens e adultos é resultado da seguinte interpelação: o que te faz gostar de uma leitura? A resposta, no entanto, segue em outra direção. Ela não só se desviou do tema proposto, como introduziu outro, resultado da interação. Mais do que dar a conhecer sua definição de leitura, o que poderia ter sido feito pela apresentação de uma definição descritiva a leitura é..., a educadora póe em relação posicionamentos sobre o mesmo objeto, não coincidentes e controversos. Os dois posicionamentos que apresenta são orientados para uma relação de contraste: a leitura/ato solitário - você e o livro - por meio da voz da tradição (anônima), e a leitura/momento de diálogo, sendo o último aquele que quer validar, que está associado à sua pessoa (vozes provenientes, provavelmente, de seus estudos sobre a leitura, de sua formação inicial e continuada como educadora e da experiência na educaçáo de pessoas jovens e adultas). Seu movimento argumentativo admite a existência de outros pontos de vista sobre a leitura, ao mesmo tempo em que se alinha a uma tendência específica. Coexistem em seu enunciado a(s) voz(es) da tradição e aquela que tornou própria. Ao evocar outro ponto de vista, que diverge do seu, opóe-se ao primeiro e assume o seu: eu vejo assim. É a dinâmica própria da enunciação, que possibilita que, num mesmo contexto, pessoas possam se referir à leitura de modos tão variados.

Ao discorrer sobre a leitura, neste artigo, espera-se trazer à baila significaçóes produzidas e constituintes dos discursos sobre esse objeto. Tais discursos (re)constroem, valoram e revelam os sentidos possíveis atribuídos a 
esta prática social, porque historicamente situados, recobertos por complexos axiológicos (ideologicamente constituídos), impregnados por múltiplas vozes sociais ${ }^{3}$. São esses movimentos discursivos de pôr em contato, de comparar, de colocar em jogo essas significaçóes e os sentidos atribuídos socialmente ao ato de ler que se busca apresentar e que se constituem em chaves de interpretação dos enunciados que circulam em vários campos: o das políticas educacionais e culturais, o acadêmico-científico, o pedagógico, o da mídia, entre outros.

Em sociedades complexas, diferenciadas e hierarquizadas como a brasileira, referir-se à leitura implica abarcar relaçóes operadas entre e no interior de classes sociais e grupos, que evidenciam fenômenos sociais. Um deles é o fenômeno da legitimidade - de crenças coletivas que edificaram a leitura como prática necessária e altamente desejável a todos, e que criaram categorias que permitem (des)classificações e (des)qualificaçóes dos modos de fazer, de objetos a consumir, das disposições, de hábitos e gostos (LAHIRE, 2002, 2006). Outro é o da desigualdade, que diz respeito à distribuição de oportunidades de acesso, à difusão de práticas, competências e objetos, que também traz em seu bojo a necessidade da leitura como prática cultural desejável. Náo se trata de clivagens determinadas a partir das categorias classe, grupo ou áreas sociais a que os sujeitos pertencem, mas, diversamente, condicionadas ao modo como a leitura, seus objetos e modos de fazer podem ser aprendidos, manipulados e compreendidos, bem como aos instrumentos culturais disponíveis e que entram em jogo nessas três operaçóes (apreensão, manipulação e compreensão) (CHARTIER, 2001; LAHIRE, 2006).

É a respeito desse jogo de posiçóes que serão tecidas as consideraçôes sobre a leitura e o modo como vem sendo abordada nas três últimas décadas. Nesse período, diversas significaçóes e sentidos têm lutado para se fazer presentes, para impor uma única verdade, universalizar-se, controlar a multidão de discursos e finalizar o diálogo. Focalizar esse jogo permite, de um lado, compreender em que bases o discurso da tradição e o cânone $e^{4}$ foram produzidos e converteram-se em divisores de águas capazes de distinguir grupos e pessoas, de definir o que conta, o que tem valor e, até mesmo, de afirmar que "o brasileiro não é leitor" ${ }^{5}$. De outro, permite apreender as oposiçóes e contra-argumentos que vêm sendo tecidos por diversas áreas do conhecimento, a partir dos mais variados interesses e motivaçóes. Implica tomar consciência dos significados sociais que circunscrevem os 
sentidos atribuídos às práticas e aos modos de participação dos sujeitos e que, portanto, são constitutivos dos discursos proferidos e das identidades construídas. Próprios dos sistemas de significação cultural, tais significados e representações, em relação de maior ou menor dominância no jogo social, são apropriados e (re)significados em interação. Na seção seguinte, as vozes sociais e sentidos disputados são examinados, fazendo corresponder os debates, as políticas culturais e educacionais, as pesquisas científicas, as campanhas e açóes educativas atuais voltadas à leitura, bem como a acepção assumida, que tem trazido à cena produçóes locais, leitores singulares, leituras e objetos multivariados.

Sabe-se do risco de simplificar um campo complexo e heterogêneo inerente ao intento proposto: a classificação e organização de significados e representaçóes socialmente atribuídos à leitura. Esse modo, no entanto, mostra-se produtivo quando se focalizam práticas culturalmente construídas e se quer compreender o que as pessoas fazem com a escrita e como esta ação se reorienta tanto para o próprio sujeito quanto para o outro. Não se trata de uma organização de discursos em polos opostos, dispostos num continuum - esta metáfora não pareceu ser suficiente para abarcá-los -, tampouco da demonstração de uma adesão fiel a um ou a outro. $\mathrm{O}$ que é assumido neste artigo é que os discursos sobre a leitura são formados e transformados por sistemas de significação culturais, gerando outros discursos. Nessa perspectiva, parece melhor tratá-los como compósitos, constituídos por diferentes substâncias, que se prestam a variadas funçóes, mas em cuja análise se encontram os traços de seus componentes. $\mathrm{O}$ convite é para que se considere a explanação sobre esses enfoques como matériasprimas sociais disponíveis, a partir das quais se misturam e surgem novas significaçóes e vozes sociais, percebidas nos discursos sobre a leitura.

\section{Enfoque da unidade}

Um dos significados correntes que exerce grande influência em variados âmbitos sociais tem como eixo a ideia de que a leitura é um ato invariável e único, com efeitos homogêneos sobre os sujeitos. Esse modo de concebê-la opera, em maior ou menor grau, com um conjunto de significados, seja no sentido da normatização, seja sobre a frequência e os modos de ler, seja para impor, prescrever e categorizar objetos, tipos de consumo e consumidores. A 
criação da norma, como explicado por Bauman (2005), tem como função excluir do domínio do permitido os atos que seriam autorizados não fosse sua presença. Opera com conceitos, convençóes e práticas que privilegiam uma determinada formação social, como se esta fosse natural ou universal ou, ainda, como se fosse o ponto de chegada de um curso normal de progresso e desenvolvimento. Trata-se de um processo que se concretiza, segundo Semprini (1999, p. 93), "eliminando-se a diferença, reduzindo ao silêncio vozes discordantes e transformando em obrigação universal o que é somente um ponto de vista particular." Define-se, portanto, pela maior ou menor proximidade daquilo que se constituiu como legítimo e por sua relação com a cultura que se quer dominante. Alinha-se a essa concepção a noção de que o ato de ler, além de altamente desejável a todos, com poderes para transformar mentalidades, valores, consciências e hábitos, é "capaz de eliminar barreiras sociais, culturais e econômicas”. (ABREU, 2001, p. 141). ${ }^{6}$

Fundado num quadro epistemológico de tradição etnocêntrica, monocultural, universalizante e uniformizante, a Leitura (doravante, sempre que o termo estiver grafado com inicial maiúscula, outorga-se o mesmo estatuto dos substantivos próprios, de caráter unitário), assim compreendida, assumirá diversas nuances que privilegiam a unidade. Não é preciso estudá-la, dado seu caráter unitário (uma única forma legítima). Interessa saber sobre o hábito e a frequência daqueles que leem e possuem as habilidades para fazê-lo - daqueles que pertencem, em maior ou menor grau, ao domínio governado pela norma -, e sobre sua distribuição em determinados espaços, grupos e âmbitos sociais.

Essa abordagem pode ser identificada em estudos sociológicos sobre a leitura que oferecem as bases para o desenvolvimento de políticas culturais e educacionais. Também se prestariam a esquadrinhar a distribuição e a difusão de determinados objetos de leitura tomados como legítimos, edificantes e de caráter transformador, e as formas de consumo adequadas a esses objetos e dignas de serem feitas. Promoveriam a determinação de grupos e populaçóes em que a Leitura - sua intensidade, sua frequência e seu valor formativo - se encontraria ausente ou ameaçada por outras formas de lazer (como os programas de televisão), pela falta de conhecimentos, competências e informaçóes. Tais investigaçóes visariam à proposição de açóes para alterar esse quadro. Também se manifesta em estudos sobre a história do livro que buscam identificar a difusão do hábito da leitura numa dada população, as 
características das escolhas dos leitores em matéria de títulos e gêneros que compóem bibliotecas particulares, e ainda os objetos da produção cultural numa dada época e para determinados grupos (GALVÃO; BATISTA, 1999).

A ênfase desses estudos recai nos sujeitos (quem), nos objetos (o quê), no onde e no quando da leitura, tendo a posse e a presença do material impresso como determinantes dos leitores e das leituras. Algumas consequências operadas nos estudos desenvolvidos a partir desse enfoque são a associação direta entre a posse ou a presença de determinado conjunto de textos em grupos ou camadas sociais com mentalidades e visóes de mundo, em períodos específicos; o estabelecimento de correlaçóes diretas entre classes sociais e produçóes culturais a ela destinadas, e a pressuposição de uma relação direta entre o texto e uma recepção determinada mais pelo objeto do que pelo leitor. $\mathrm{O}$ que se observa é que esses estudos não possibilitam compreender os modos pelos quais os textos eram apropriados por seus leitores e os usos que deles faziam (BOURDIER; CHARTIER, 1996; GALVÃO; BATISTA, 1999; CHARTIER, 2001).

Consoante com o enfoque centrado na unidade, também se encontram pesquisas desenvolvidas nas décadas de 1960 e 1970, voltadas a demonstrar que a escolarização, a aquisição da linguagem escrita e o acesso à leitura seriam sinônimos de progresso social e, no âmbito individual, seriam responsáveis pelo desenvolvimento cognitivo e pela aquisição de habilidades e conhecimentos necessários para adequar-se às sociedades modernas. Nesse período, essa intensa produção reuniu diversas áreas do conhecimento, como a Antropologia, a Linguística, a Psicologia e a História. Destacamse as produçôes de Goody (1987), Ong (1998 apud RIBEIRO, 1999), e Olson e Torrance (1995), que, nessa vertente, atribuíram à escolarização e à linguagem escrita efeitos homogêneos e universais responsáveis pela transformação das sociedades e da mente humana.

Os expoentes desse modelo de interpretação trataram o domínio da linguagem escrita como independente do contexto social, como variável autônoma cujas consequências para a sociedade e para a cognição são intrínsecas a essa linguagem. Suas produçóes correspondiam a uma percepção da realidade motivada pela distinção entre grupos sociais e entre diferentes sociedades, pela justificativa de processos de dominação, civilização e assimilação entre culturas, pela dicotomia letrados/iletrados. A ênfase desses estudos recaiu sobre o impacto da aquisição e domínio da escrita por sujeitos, 
grupos e sociedades tidos como receptores passivos, sobre os quais os efeitos se dariam de modo homogêneo, bem como do caráter aparentemente neutro e universal das práticas sociais de uso da escrita em instituiçóes e agências sociais que as distribuem e as promovem. Tais efeitos englobam desde "a participação na espécie [humana] até a posse de qualidades espirituais" (KLEIMAN, 1995, p. 35).

Grande parte dessas pesquisas e estudos subsequentes serviu para orientar pesquisas de larga escala, que mensuravam capacidades, objetos, hábitos e competências leitoras de populaçóes, para influenciar modelos de desenvolvimento de países considerados atrasados ou em vias de desenvolvimento, para pautar legislaçóes, políticas públicas, programas e açóes na esfera estatal. E continua influenciando o desenho e a implementação de políticas culturais e educacionais. Privilegiou desse modo "uma formação social como se fora natural ou universal ou, pelo menos, o ponto final de uma progressão normal do desenvolvimento de destrezas cognitivas" (GEE, 2004, p. 38).

Se tais pressupostos atualmente alimentam a medição de competências, quantificam e qualificam objetos e leitores, também funcionam como alertas da falta de leitores e da constante situação de crise da leitura. Os discursos da falta e da precariedade nada mais são do que a outra face da mesma moeda: a da leitura redentora, mitificada. Tais discursos atravessam a história da leitura no Brasil em diversos períodos, como aponta Abreu (2001, p. 154), e são "decorrentes da delimitação implícita de um certo conjunto de textos e de determinados modos de ler como válidos e o desprezo aos demais." Procedem de uma premissa comparativa entre sociedades constituídas a partir de contextos sociais, políticos, econômicos e culturais extremamente distintos, como, por exemplo, a leitura e os materiais impressos consumidos no Brasil versus os dos países da Europa Ocidental ou os dos Estados Unidos da América. Tendem a produzir avaliaçóes de níveis culturais e educacionais no interior de sociedades e a demarcar as distâncias que separam as práticas letradas hegemônicas das de segunda categoria ou "bastardas".

Encontram-se, no livro e em alguns gêneros literários e de divulgação científica, seguidos dos jornais e revistas, os maiores representantes do patrimônio cultural ou da Cultura a que todos deveriam ter acesso, depreendendo-se daí os critérios que definem os bons e maus usos da leitura. O caráter etnocêntrico desse enfoque evidencia-se no modo como as 
dicotomias são fixadas nas sociedades letradas e no processo de identificação das pessoas - leitor é aquele que lê o livro ${ }^{7}$, que gosta e apresenta uma disposição positiva diante de certos gêneros, os literários preferencialmente, que tem o hábito de ler e lê com frequência e que pratica certos tipos de consumo cultural. Ao estabelecer uma hierarquia de objetos, de gêneros e de suportes, aqueles que se filiam a esse enfoque definem o que é ler e, na mesma operação, escalonam os leitores segundo os objetos que consomem, as oportunidades de acesso e a frequência com que leem, excluindo os não leitores (ABREU, 2001; TARDELLI, 2003).

Como bem em si e conjunto de competências que se adquirem e que constituem o patrimônio cultural legítimo, está pressuposto que a leitura deve ser transmitida e difundida a todos. Os efeitos dos fenômenos da legitimidade e da desigualdade, da crença no poder modificador do livro e de alguns objetos dignos de ler, podem ser pensados em relação ao processo de distinguir sociedades, grupos e pessoas.

Assim, aqueles que creem no mito podem buscar a identificação com esse "leitor", talvez impossível, já que idealizado, que possui certas competências, disposiçóes e gostos, tendo a escolarização como a via de iniciação e o meio para chegar à Leitura. Esse leitor parece ter se apropriado dos modos de ler dos críticos literários (KLEIMAN, 2001c), dos intelectuais, de certa classe de pessoas que incluem uns poucos que leem os livros valorados positivamente: "livros lidos por muitos não servem; bons são aqueles que poucos leem, menos entendem e menos ainda gostam." (ABREU, 2001, p. 155). Quanto menos praticada e partilhada, mais forte o valor distintivo da Leitura, pois se tem implícito que a maioria não é leitor ou não se comporta dentro dos padróes e não realiza o tipo de leitura almejado pela norma.

O fenômeno da legitimidade é o que possibilita que a Leitura seja amplamente reconhecida, inclusive por aqueles que a ela não tiveram acesso: os que não praticam a leitura segundo o padrão, que não formaram os gostos e não adquiriram os hábitos que lhes permitiriam estar em consonância com o modelo, que não se identificam como leitores e/ou que resistem à norma preconizada. A possibilidade de identificação é também um fator de estratificação. Há os poucos que se identificam como leitores e mantêm e constituem a norma, e aqueles muitos que se ressentem, resistem, renegam, rompem e que se veem estigmatizados, estereotipados (BAUMAN, 2005). 
As mesmas representações podem ser percebidas no desenho e implementação de políticas educacionais e culturais de tipo universal, no sentido da democratização do acesso, da mudança/aquisição de hábitos e valores, da reparação de desigualdades no que concerne à leitura. Em outras palavras, na produção de projetos sociais necessários, já que nada no mundo é como deveria ser e, portanto, ações preventivas e corretivas ou investidas antecipadas são necessárias para ordenar a realidade a partir de um ponto de vista único e superior. Os efeitos de políticas cunhadas sobre pressupostos universalizantes e etnocêntricos acabam por abarcar o excluído por meio de sua própria retirada (BAUMAN, 2005). Especificamente em relação às políticas em torno da leitura, Tardelli (2003, p. 16) afirma que

[...] embora a busca pela garantia de um necessário acesso à escrita a todos pudesse representar uma forma mais democrática de formação de leitores e de inclusão social, esta significação da leitura - aliada à posição letrada elitista - na verdade, apenas ameniza o seu caráter excludente.

Se as políticas culturais são desafiadas a persuadir um amplo público em torno de uma determinada prática (a leitura para o prazer, para a evasão, por exemplo) e de um objeto de consumo (o livro), as políticas educacionais se firmam a partir de outra dinâmica. O sistema escolar, por sua obrigatoriedade legal, organização hierárquica e permanência de longo prazo, tem sido um terreno fértil para a proliferação dos ideais focalizados nessas políticas. Durante grande parte de sua história, a educação escolar tem desempenhado o "papel de agenciar a relação entre culturas com poder desigual [...], contribuindo para a manutenção e difusão de saberes mais fortes contra formas culturais que eram consideradas como limitadas, infantis, erradas, supersticiosas" (FLEURI, 2003, p. 23).

Segundo Lahire (2006), o sistema escolar dispóe dos meios para formar gostos, impor seus veredictos e julgamentos aos futuros consumidores. Isso se deve ao fato de que está alicerçado numa visão hierárquica (das relações sociais e/ou com o conhecimento) e em valores fundados na diferença, seja nos níveis e progressão que organizam o sistema (ensino fundamental, ensino médio, ensino superior, por exemplo), seja nas oportunidades de formação oferecidas (educação regular, suplência, ensino profissionalizante, por exemplo). A escola 
é uma das principais vias para o aprendizado e acesso às maneiras de ler e de disseminação dos objetos que merecem ser consumidos pelos leitores, na qual se depositam expectativas sociais sobre a formação de leitores e, como afirma Dionísio (2000, p. 41), "se geram e mantêm papéis discursivos e sociais e se determinam acçôes legítimas naquele contexto - aquilo que é possível dizer e fazer e aquilo que não é possível dizer e fazer.” As práticas empreendidas no contexto escolar estariam pautadas por processos de distribuição desigual de oportunidades, interferindo desde muito cedo nos percursos e possibilidades dos estudantes representantes dos mais variados grupos sociais e contribuindo para manter hierarquias e a dominância de certos grupos em relação a outros.

No plano pedagógico, a suposição da neutralidade cultural do ato de ler, de sua instrumentalidade e eficácia social, engendra em seu aprendizado a suposição de que sua aquisição é sempre possível, dando-se uniforme e progressivamente; equivale a aprender uma técnica que depois será transferida a outros objetos e tipos de consumo. Nesse caso, só fracassariam os pouco capazes, os sem condição para se escolarizar, os que apresentam uma disposição negativa diante do ato de ler, deslocando a responsabilidade do sucesso/fracasso da aprendizagem da instituição e de suas propostas educativas, bem como das autoridades constituídas para essa tarefa, para o indivíduo e para o esforço empreendido por ele (KLEIMAN, 1995).

Um enfoque calcado, portanto, numa visão elitista de cultura, torna invisíveis as práticas comuns de leitura. Um grande conjunto de pesquisadores do campo da Antropologia, dos Estudos da Linguagem, da História do Livro e da Leitura e dos Estudos Culturais, opositores a um enfoque etnocêntrico e universalizante, assevera a necessária mudança das lentes com as quais se observa o mundo social e as práticas humanas. Tratase de abrir mão do enfoque da unidade e assumir um outro, fundamentado numa epistemologia multicultural (SEMPRINI, 1999) e ancorado nas ideias de multiplicidade, de diferença, de diversidade, de heterogeneidade e de variação nos modos de praticar a leitura, nos objetos dados a ler e nas formas de apropriação do texto pelos sujeitos.

\section{Enfoque da pluralidade}

Outra representação que se quer destacar é fortemente influenciada por uma matriz culturalista, fundada pelos estudos etnográficos de Franz 
Boas, em oposição ao paradigma etnocêntrico e universalizante nas Ciências Sociais. $\mathrm{O}$ enfoque da pluralidade não se encontra alocado numa única via, mas multiplica-se em interpretaçóes, o que tem consequências para os modos de se compreender a leitura, leitores e objetos dados a ler. Uma de suas características principais é o fato de desnaturalizar práticas e dissolver qualquer movimento em torno de uma unidade cultural ou de um pretenso destino evolutivo para o qual todas as sociedades rumariam.

Sob este enfoque, as práticas culturais são tomadas como criações humanas variáveis e o trabalho do pesquisador consiste na sua descrição, com os objetos culturais e as relaçóes sociais que se estabelecem. Como decorrência, tem-se a distensão do campo das práticas de leitura, abrindo espaço para admitir variados modos de fazer, tem-se a distensão de objetos, de disposições, gostos, enfim, de possibilidades de ação humana perante a escrita. Isto porque essa abordagem atua no sentido de ampliar o horizonte dos objetos da leitura, dos modos, comportamentos e preferências diante do ato de ler, quebrando dicotomias entre objetos melhores e piores, leitores e não leitores, e, sobretudo, eliminando a aura de inacessibilidade a certos materiais e gêneros do discurso. Essa forma de compreender as realidades culturais e de interpelá-las tem o potencial de fazer emergir uma variedade de práticas e um número surpreendente de vozes e discursos apagados ou não reconhecidos por um enfoque etnocêntrico, além de permitir a manifestação de pluralidades no interior de sociedades e grupos humanos.

\section{O plural sob o estatuto da neutralidade}

Uma das variantes desse enfoque, tendo como motivação eliminar toda forma de etnocentrismo cultural, "dá importância à diversidade, preocupando-se em demonstrar que ela não é contraditória com a unidade fundamental da humanidade." (CHARTIER, 2001, p. 153). Essa variante opera sob o estatuto da neutralidade e da equivalência entre as diferenças e da exaltação e defesa de certas práticas, objetos e leitores pertencentes a grupos minoritários ou que estão ameaçados por processos de não reconhecimento, de estigmatização e de produção de estereótipos. Ocupa-se do reconhecimento de igual dignidade de universos simbólicos, da tolerância e respeito em relação a práticas culturais diversas. 
É o estatuto da neutralidade o aspecto mais criticado nesse enfoque com base culturalista ou relativista. Um dos problemas reside nos resultados de pesquisas organizadas em torno deste princípio, que focalizam a mera descrição de práticas, objetos e leitores, reduzidos a traços colecionados e descritos em si mesmos, sem que se compreenda o lugar social e sem relacioná-los à ordem simbólica e aos sistemas em que são produzidos. Sobre a neutralização de sistemas de diferenças, Chartier (2001, p. 153) lembra que "as práticas culturais sáo sempre objetos de lutas sociais que têm por risco sua classificação, hierarquização, sua consagração (ou ao contrário sua desqualificação)", não podendo, portanto, ser tomadas como um mundo à parte, com um valor determinado pela distância que se encontra da legitimidade cultural da qual é privada. A armadilha de tal assunçáo é exatamente a do risco de substituir um padráo por outro. Num movimento semelhante, em vez da Leitura, do legítimo e digno, do hábito e da frequência com que leitores (idealizados) acessariam certos gêneros, a ampliação de universos culturais levaria à valoraçẫo por si de produçôes locais, de leitores singulares, de leituras e objetos multivariados. Considera-se que o processo de substituição pode levar à restrição de aprendizagens, de experiências e de familiaridade com práticas de usos da linguagem escrita que favoreçam a participação em sociedades complexas, burocratizadas e organizadas a partir de certos padróes culturais.

Sem dúvida, a assunção do estatuto da neutralidade pode corresponder à atitude ética reivindicadora de defensores das culturas minoritárias e de grupos em situação de maior vulnerabilidade no campo social, exigindo condição de igual valor das produçóes culturais, tanto desses grupos como das dos grupos dominantes. Porém, como alerta Cuche (2002), também pode corresponder a uma atitude complacente do forte em relação ao fraco, daquele que, assegurado da legitimidade cultural, pode tolerar e admitir o(s) outro(s). Como bem analisa Osakabe (2005, p. 41), as consequências de uma abordagem como essa no campo da leitura levaram ao

[...] desenvolvimento de um movimento legítimo, mas que acabou tendo como resultado o oposto do que pretendia. Pretendia a equiparação de objetos culturais, dentro da complexidade de uma suposta totalidade cultural. O que se conseguiu foi uma visão complacente por parte de uma Inteligentzia culposa 
que trouxe a ilusão da legitimidade e cidadania a esses objetos, mas que os mantém ciosamente etiquetados como representantes do âmbito restrito de sua cultura.

As contradiçóes econômicas e sociais no interior de sociedades altamente hierarquizadas, como a brasileira, as diferenças substanciais na distribuição de oportunidades de acesso a bens culturais relacionados à escrita, no interior dos grupos humanos, não são fenômenos neutros. As culturas originam-se nas e a partir de relaçóes sociais, marcadas pela desigualdade, por assimetrias entre culturas, e que resultam da própria hierarquia social.

O equívoco é explicado por Cuche (2002), que afirma que um princípio metodológico, advindo dos estudos cunhados sob a matriz relativista cultural, foi transformado por pesquisadores em julgamento de igual valor de culturas que ocupam posições diferentes nos campos social, econômico e político. Segundo o autor, a alternativa a essa abordagem redutora seria partir da premissa de que as culturas dos diferentes grupos se encontram em maior ou menor posiçáo de força em relação às outras e que é necessário dar igual atenção às distintas culturas produzidas por sujeitos e grupos, sem que isso leve à conclusão de que todas têm igual valor simbólico. $\mathrm{O}$ autor propóe que sejam compreendidas a partir dos conflitos e das tensóes que as constituem e dos quais resultam.

De um lado, a abordagem relativista tem como mérito o princípio ético e metodológico do reconhecimento da diversidade, da validação de diferentes manifestaçóes culturais e da contestação a padróes hegemônicos e da, como já dito, afirmação de vozes e discursos apagados ou desconhecidos. $\mathrm{O}$ reconhecimento da diversidade acarreta ainda a desnaturalização da perspectiva elitista, o que resulta fundamental para os processos reivindicatórios que se originam no seio de grupos subalternos ou em condição de desvantagem social. Por outro lado, se operada sob o estatuto da neutralidade, atenua as desigualdades, obscurece o conjunto de exigências em relação aos padróes da cultura escrita que colaboram para o exercício da cidadania em sociedades letradas.

A assunção do enfoque da diversidade, no plano pedagógico, pode dar às propostas e açóes educativas contornos variados. $\mathrm{O}$ reconhecimento da 
diversidade pode resultar numa ação compensatória, que estimula os sujeitos a abandonarem suas práticas culturais, suas preferências e objetos de leitura, em favor de outras tidas como superiores, melhores ou preferenciais, o que resultaria contraditório. Pode, por consagrar a diversidade, limitar o acesso dos sujeitos a outras práticas de leitura, novos objetos, variadas formas de ler - aprendizagens que, se desenvolvidas, colaborariam para transcender o local. E, por fim, pode propor uma ação ética da tolerância e do respeito, sem que as diferenças sejam discutidas em sua origem e como resultados sociais.

De outra feita, reconhecer que as práticas culturais relativas à leitura encontram-se em maior ou menor grau atravessadas por conflitos e lutas sociais não deve reduzir seu estudo somente a essas últimas. Este tipo de análise também leva ao imobilismo, em especial, quando suas interpretaçóes são redutoras ou deterministas, supondo "que o mais forte está sempre em condiçóes de impor pura e simplesmente sua ordem (cultural) ao mais fraco." (CUCHE, 2002, p. 145). Propóe, como alternativa, um movimento de retorno ao uso original do relativismo, que fazia dele um princípio metodológico, resumido da seguinte maneira pelo autor :

[... ] estudar todas as culturas, quaisquer que sejam a priori, sem compará-las e ou medi-las prematuramente em relação a outras culturas. Privilegiar a abordagem compreensiva e, definitivamente, adotar a hipótese que mesmo no caso das culturas dominadas, uma cultura funciona sempre como uma cultura, jamais totalmente dependente, jamais totalmente autônoma. É preciso saber considerar a dependência ou ainda a interdependência. E, através de uma justa aplicação do princípio metodológico, é preciso também saber localizar a autonomia (relativa) que caracteriza cada sistema cultural. (CUCHE, 2002, p. 241, grifos do autor).

Certeau (1994) sugere que há uma separação entre a norma e o vivido, a injunção e a prática, o sentido visado e o produzido. É nesse espaço, da recepção e da apropriação, que se insinua outra produção, que origina gestos, pensamentos, gostos, disposiçôes, discursos e práticas diversos daqueles que se pretendiam inculcar sobre a Leitura. Mesmo os grupos e sujeitos em posição de maior vulnerabilidade e fraqueza não se encontram 
desarmados no campo social, não estão desprovidos de recursos culturais próprios e, sobretudo, de capacidade de reinterpretar e de se apropriar das produçóes culturais que não fabricam e que lhes são impostas em maior ou menor grau. Nem inteiramente dependentes, nem inteiramente autônomas, nem pura imitação, nem pura criação, as culturas de grupos em situação de vulnerabilidade precisam ser observadas na e a partir da situação de dominação em que são construídas e que as constituem. Sofrer processos de dominação não significa aceitação e resignação. A força de modelos culturais não anula o espaço próprio de sua recepção, não se resume à submissão, à interdição e à imobilidade, podendo assumir os mais diversos contornos: de resistência, de rebeldia, de dormência, de recriação, entre tantos outros.

Em Certeau (1994), essa ação humana resulta num conjunto de maneiras de viver com a dominação, que se fabrica no cotidiano, nas atividades ao mesmo tempo banais e renovadas a cada dia, uma produção multiforme e disseminada, portanto, visível apenas nos modos de operar desses sujeitos, nos usos que fazem dos produtos culturais. Nas proposiçôes desse autor, encontra-se uma nova forma de perceber a relação entre produtos culturais e consumidores e, especialmente, entre autor-texto-leitor, que se insere obrigatoriamente num sistema social, político e econômico que organiza sociedades e os grupos humanos. Do mesmo modo como desfaz a ideia da inércia do ato de consumir, o autor aponta para um leitor que se apropria do texto, que define sentidos, que vaga pelos interstícios das páginas impressas, produzindo uma pluralidade de significaçóes.

É a partir do contexto social e histórico específico que a leitura, seus objetos, os modos de ler e os leitores são constituídos. É no jogo social, em que sujeitos ocupam posiçóes peculiares, que se pode acender às múltiplas maneiras de fazer e às significaçóes dessas práticas.

\section{O plural sob a perspectiva sócio-histórica cultural}

Ao estabelecer uma relação de interdependência entre três pressupostos - a diferença e a heterogeneidade nas práticas de leitura, a multiplicidade de maneiras de ler e de objetos da leitura e a variação gerada pelas condiçóes sócio-históricas e culturais -, este enfoque pluralista apresenta novas formas de compreender, abordar e problematizar esse objeto multifacetado - a leitura -, tendo como elementos centrais os textos e seus leitores. Nesse 
enfoque, as práticas de leitura não se encontram inextricavelmente relacionadas a um único objeto (o livro), não se definem por uma forma particular de ler (silenciosa e solitária). Tampouco se localizam exclusivamente na mente das pessoas, como um conjunto de habilidades ou capacidades a serem aprendidas e posteriormente aplicadas, e também não residem nos textos. Não podem ser alcançadas meramente pela determinação de sua frequência e hábito, pela posse de objetos ou pelo pertencimento estrito a classes ou grupos. Afinal, como toda atividade humana, a leitura é essencialmente social e pode ser localizada na interação entre as pessoas (KLEIMAN, 1995, 2001a).

Chartier (2003, p. 146) propóe para os historiadores da leitura e do livro o reconhecimento da leitura como atividade inventiva e criativa. Reafirma a necessidade de "considerar para cada época como se estabelecem relaçóes complexas entre as formas impostas, mais ou menos restritivas e imperativas, e as identidades afirmadas, mais ou menos radiosas ou contidas." $\mathrm{O}$ pesquisador teria duas exigências, pelo menos. A primeira refere-se ao exame do ato de ler em suas relaçóes com a história, a sociedade e a cultura, fazendo desse exame o espaço de integração do conjunto de estudos sobre esta atividade humana. A segunda lida com a apreensão do modo pelo qual as condiçóes histórico-sociais particulares fazem emergir modos de ler, usos da leitura e suas significações, dando atenção ao ato de ler e às significações plurais que os leitores produzem ao se apropriarem dos textos, ao exame da historicidade dos objetos de leitura, das categorias que os classificam e das práticas discursivas e não discursivas que o envolvem.

Alinham-se a essa perspectiva os Estudos do Letramento que concebem as práticas de uso da escrita como algo necessariamente plural: sociedades diferentes e os grupos sociais que as compóem têm variadas formas de letramento, tendo a escrita variados efeitos sociais e mentais em contextos sociais e culturais específicos. O letramento é visto como um conjunto de práticas discursivas, como formas de usar a língua e outorgar sentido tanto à fala como à escrita. Essas práticas discursivas estão integralmente conectadas com a identidade ou consciência de si mesmo das pessoas que as praticam; uma mudança nas práticas discursivas resulta em mudanças de identidade (BARTON; HAMILTON; IVANIC, 2000; GEE, 2004; KALMAN, 2004; KLEIMAN, 1995, 2001b).

Para tanto, propóe-se o reposicionamento das pesquisas etnográficas e interculturais, deixando de lado a prática de comparaçóes e distinçóes e 
abrindo espaço para a percepção das diferenças, não como equivalentes, nem como déficits, mas como possibilidades inscritas e socialmente situadas (STREET, 2004). O reconhecimento dos problemas de uma abordagem etnocêntrica das práticas de uso da escrita em diferentes sociedades e grupos humanos impulsionou o desenvolvimento de um modelo alternativo, que se pauta por uma compreensão etnográfica e teoricamente mais adequada aos significados das práticas letradas na vida das pessoas.

Kleiman e outros pesquisadores ${ }^{8}$ têm colaborado para estabelecer outros pontos de vista sobre as práticas de uso da escrita por grupos não ou pouco escolarizados, sobre a formação de leitores e sobre as identidades e práticas educativas de professores que se dedicam ao ensino da língua materna. Para os filiados a essa abordagem, é preciso debruçar-se sobre os fatores sociais, considerando as diversas esferas da atividade humana, determinadas por sua inserção cultural. As práticas letradas, a leitura, a escrita e a oralidade são tomadas como fundamentalmente ligadas às estruturas sociais; encontramse interpenetradas em complexos sistemas culturais e dentro de estruturas de poder. Nas palavras de Street (2004, p. 90, grifos da autora):

A construção do letramento está imbricada nas práticas discursivas e nas relaçôes de poder na vida cotidiana: está socialmente construída, materialmente produzida, moralmente regulada e tem significado simbólico que não pode reduzir-se a nenhum destes ${ }^{9}$.

As pesquisas sobre letramentos empreendidas a partir desta vertente, fundadas numa epistemologia multicultural e nos princípios da heterogeneidade e multiplicidade, têm colaborado para a revisão do papel da linguagem escrita nas sociedades e para atualizar sentidos atribuídos à alfabetização e à escolarização, bem como se voltam para o reconhecimento das práticas de uso da escrita que são locais ou vernaculares, observando a variação e a diferença nos modos de fazer de grupos, os significados atribuídos a essas práticas, as identidades que se produzem em interação e os objetos culturais que são acionados. Potencialmente, a abordagem situada dos estudos do letramento, como indica Kleiman (1995), colabora para operar mudanças em realidades desiguais, nas quais se perpetuam hierarquias e assiste-se à crescente marginalização e estigmatização de grupos sociais por meio de instrumentos como a escrita. 
Muitas dessas contribuições são advindas dos estudos realizados pela escola New Literacy Studies - NLS (Novos Estudos do Letramento) (BARTON; HAMILTON; IVANIC, 2000; GEE, 2000; HEATH, 1989; STREET, 1984). Segundo Stromquist (2001), a abordagem sociocultural da NLS enfatiza o reconhecimento dos letramentos em suas comunidades de práticas, desempenhando funçóes diversificadas de acordo com os contextos e com os objetivos que guiam os sujeitos nesses eventos. Essas práticas são compreendidas como modelos e eventos culturais que dão forma a comportamentos, a significados, a valores e atitudes, concretizados e assumidos nos usos da leitura e da escrita. Tais práticas são meios culturais de utilização da escrita,

modeladas por instituiçóes sociais e por relaçóes de poder, e algumas são mais dominantes, visíveis e influentes que outras. [...] têm propósitos bem definidos e estão relacionadas a metas sociais e práticas culturais mais amplas. [...] mudam, e novas práticas são frequentemente adquiridas por meio de processos informais de aprendizagem e estabelecimento de sentido. (BARTON; HAMILTON; IVANIC, 2000, p. 9).

Essa abordagem exige, portanto, considerar as elaborações, procedimentos e demandas a que os sujeitos devem responder em diferentes situaçóes de seu cotidiano e as posiçóes em que se encontram tanto nos eventos como no campo social mais amplo, já que, nas açóes humanas, entram em jogo as relaçóes de poder, as tensóes, as desigualdades que caracterizam a vida social, política e econômica (ZAVALA; NIÑO-MURCIA; AMES, 2004). É por meio de uma metodologia de caráter etnográfico, de cunho qualitativo, que a unidade de observação é o evento de letramento. A partir dele chega-se à análise das práticas: o que as pessoas fazem com a escrita e o que textos e situaçóes significam para elas. Alguns estudos lançam mão de instrumentos de pesquisa variados, tais como a história de vida, a observação participante, a aplicação de entrevistas e grupos focais, a análise iconográfica (imagens de eventos de letramento) e documental, entre outros, predominantemente qualitativos. Focalizam a função e o significado do letramento pelos próprios participantes, descrevem o modo como as pessoas se engajam ativamente 
nos eventos e como este engajamento impacta as interaçóes e suas escolhas (BARTON; HAMILTON; IVANIC, 2000; KLEIMAN, 1995).

Assumir a diferença e a heterogeneidade implica negar resultados ou efeitos homogêneos da participação em práticas sociais nas quais a escrita é central e tomá-los como variáveis, dependentes dos contextos, papéis, artefatos culturais, objetivos e formas de interaçáo que guiam os sujeitos em atividade, o que remete à possibilidade de obter configuraçóes singulares, no interior de grupos sociais e da complexa e diversificada sociedade moderna (LAHIRE, 2002, 2006; OLIVEIRA; VÓVIO, 2003). Leitores interagem em distintos mundos letrados, instanciados pelos instrumentos culturais de que dispóem e podem lançar mão (nesse caso, discursos escritos) e mediados por relaçóes interpessoais. Suas possibilidades de ação e de tomar parte em práticas culturais, bem como capacidades e repertórios construídos, podem, portanto, variar.

A vertente sócio-histórica cultural tem propiciado a formulação de novas orientaçóes para abordar o processo de ensino e aprendizagem da linguagem escrita. É importante ressaltar que a disseminação desses estudos no Brasil esteve diretamente relacionada às novas problemáticas que se colocavam no horizonte do processo de escolarização (SOARES, 1998), entre elas a expansão e democratização do acesso à educação básica (sem as mudanças que deveriam acompanhar este processo); ao fracasso escolar identificado pela implementação de sistemas nacionais e locais de avaliação; ou ainda à compreensão do que as pessoas efetivamente fazem com a linguagem escrita, para além de saber sobre seu estado ou condição de analfabetas (RIBEIRO, 1999, 2003). O reconhecimento das diferentes práticas de leitura tem amplificado a atribuição educativa e complexificado a formação de leitores, já que o que se espera dos atores sociais está relacionado simultaneamente às demandas culturais locais e àquelas globais, preconizadas por instituiçôes ou domínios sociais. Como bem sintetiza Dionísio (2005, p. 76), formar leitores envolve

[...] manter um repertório vasto e flexível de práticas, desempenhar papéis e activar recursos que dêem expressão às dimensôes operativas, culturais e críticas, actuando, tanto: como decodificador, pela mobilização de recursos necessários para abrir o código dos textos escritos, reconhecendo e usando 
traços e estruturas convencionais da organização do texto; como participante textual, participando na construção de sentidos, tendo consideração, por relação com suas experiências e conhecimentos sobre outros discursos, textos e sistemas de significação, os sistemas de sentido específicos de cada texto; como utente de textos, usando-os pragmaticamente, negociando as relaçóes sociais à volta dos textos, sabendo sobre eles e agindo nas diferentes funçôes sociais e culturais que eles desempenham na sociedade (por exemplo, na escola) e compreendendo que estas funçôes afectam o modo como os textos são estruturados, o seu tom, o seu grau de formalidade e a organização dos seus elementos constitutivos.

Nesse sentido, os processos escolares estariam desafiados a pelo menos dois movimentos. $\mathrm{O}$ primeiro dirige-se para o estudo das práticas de letramento locais, a fim de reconhecê-las e incorporá-las nas açóes educativas que têm lugar na escola. Os letramentos locais, nem sempre visíveis, porque diversos dos letramentos dominantes, constituem-se em modelos alternativos geralmente funcionais, ligados à realização de atividades situadas e singulares. Por sua natureza, as tarefas de identificá-los e reconhecê-los demandam estabelecer outro ponto de vista sobre os sujeitos que os produzem e sobre os significados e valores que os sustentam. O segundo movimento é o de tomar os letramentos locais como ponto de partida para selecionar aqueles dos quais a escola se ocupará e, como propóe Kleiman (1998, p. 270), para mediar a "aquisição das práticas de letramento oficialmente legitimadas, especialmente em vista dos enormes fracassos dos programas oficiais de alfabetização", sem esquecer que práticas e modelos globalizantes ou em condição de dominância podem gerar conflitos com as práticas e identidades locais, especialmente quando tendem a impor novos valores, a substituir ou sobrepor o local (SITO, 2010; ZAVALA, 2010).

Conceber a leitura fundada em princípios da multiplicidade e do multiculturalismo traz ainda decorrências diretas para o modo como se procedem investigaçóes, especificamente para os planos a partir dos quais se analisam os dados gerados. 


\section{Algumas implicações para pesquisas sobre leitores e práticas de leitura}

Filiada ao enfoque sócio-histórico cultural, compreende-se a leitura como prática cultural situada, atravessada por hierarquias e condicionantes sociais e, como tal, produzida a partir de sistemas culturais de significação e mediada pela linguagem, o que implica incorporar uma duplicidade na orientação desta atividade humana.

A primeira dessas orientaçóes, dirigida à exterioridade, refere-se ao modo como os sujeitos se posicionam e se engajam nas interaçóes em que a leitura pode ser simultaneamente objeto do discurso (quando enunciam sobre o ato de ler e sobre si mesmos como leitores) e às relaçóes que se estabelecem entre pares à medida que açóes são efetivadas (quando compartilham ações mobilizadas para a realização da atividade, atribuem sentidos a suas ações e à própria participação, por exemplo). Como decorrência, aos pesquisadores e aos educadores interessados em reconhecer as práticas de leitura, os sentidos atribuídos a essas práticas, bem como os acervos que as perpassam, caberia o exame tanto dos enunciados proferidos sobre a leitura, imbricados em modos de fazer, em eventos de letramento, como das construçōes identitárias inerentes e em coprodução na interação com leitores e entre leituras, nas quais se afirmam o que são ou como concebem a si mesmas.

Há um primeiro plano de análise, aquele que focaliza a produção de sentidos e significados ao ato de ler. Uma possibilidade de análise experimentada por Vóvio, (2007), Souza (2009) e Sito (2010) é orientada pela perspectiva discursivo-enunciativa de Bakhtin e de seu Círculo, observando tanto as vozes - esquemas que significam, simbolizam e constroem e reconstroem a realidade, produzidos por sujeitos sociais, historicamente situados - como o processo de construção de sentidos, tomados como fundamentalmente sociais e discursivos, decorrentes da conexão entre o indivíduo e o social, definidos como ideológicos (BAKHTIN, 1981).

Os discursos sobre a leitura e as vozes sociais que os constituem podem ser surpreendidos nas enunciações por meio da identificação das significaçóes que circulam e são apropriadas e dos temas que são recusados ou acentuados e por meio da apreciação valorativa, engendrados na dimensão verbal e extraverbal das interaçóes. Estariam, portanto, indiciados nos objetos referenciados nos enunciados, emergentes das/nas situaçóes de 
investigação e eventos de letramento focalizados, como respostas ativas pertencentes a um mundo dialogizado, povoado por múltiplas vozes sociais (BAKHTIN, 1993). Observar e compreendê-los colaboram para situar, na cadeia da comunicação social, as tendências observadas e os alinhamentos preferenciais dos sujeitos aos modos de referir-se à leitura, de designarem e se apropriarem de objetos, de dizerem de si e construírem sentidos para suas experiências como leitores. Também interessa verificar movimentos de mudança e de transformação, porque, ao se apropriarem de significados estáveis e ao colocá-los a favor da interação, os participantes atualizam, refutam ou reacentuam-nos em seus enunciados, em função da identidade dos interlocutores, da finalidade da enunciação, do momento histórico e da ideologia.

Um segundo plano de análise foca as construçóes identitárias, compreendidas como discursivamente constituídas, decorrentes do dinamismo de experiências no mundo social e condicionadas por conjugações da vida sócio-histórica. As identidades são tomadas em seu caráter fluido, instável e fragmentado, dependente da interação social, da linguagem e dos sistemas de significação culturais que se têm à disposiçáo e em contínuo processo de transformação e constituição (HALL, 2003; KLEIMAN, 1998; MOITA-LOPES, 2002). São relacionadas à ordem social e cultural, sendo sua produção e o processo de identificação atuantes nas possibilidades dos sujeitos, sejam elas relativas ao comportamento, aos lugares e posiçóes sociais, à consciência ou aos próprios atos de pensar e de relacionar-se com o outro.

Afirmar-se leitor e sustentar posiçóes produzidas ao enunciar-se desse ou daquele modo demanda o exercício de seleção e de classificação, que se alimenta e revigora "pela ameaça e prática da exclusão." (BAUMAN, 2005, p. 30). Se pertenço ao grupo de leitores é porque outros náo pertencem: há outros com os quais se pode identificar e outros dos quais se quer diferenciar. Se pertenço a certa classe de leitores é porque há várias categorias que qualificam e organizam lugares para os sujeitos que praticam a leitura, usufruem de certos objetos e assumem papéis nesse espaço. Portanto, as possibilidades de ser e de produzir discursivamente quem se é decorrem do conjunto de significaçóes que se tem ao dispor, do jogo de forças para permanência, para acentuar ou apagar certas posiçóes de sujeito, e do modo como estão distribuídas as oportunidades para uso desses recursos (VÓVIO; 
DE GRANDE, 2010). Esses sistemas compreendem os recursos da história, da linguagem e da cultura, que entram na produção das identidades (HALL, 2003). Trata-se de um processo que também se encontra imbricado nas biografias e experiências pessoais que se colocam a favor dessa ação conjunta.

A segunda orientação desta atividade, interior, refere-se ao retorno para cada pessoa que toma parte dessas açóes interdependentes, que têm a linguagem como instrumento cultural, objeto do discurso e como sistema de significação com potencial constitutivo e interpretativo da realidade, das experiências e identidades. Tanto a primeira como a segunda orientação dizem respeito ao processo de desenvolvimento humano e propiciam agir de variadas formas no mundo por meio de artefatos materiais e simbólicos produzidos pelas culturas, que conformam a vida e a mente humanas, dando significados à ação. Nesse sentido, caberia aos pesquisadores e educadores perscrutarem um terceiro plano: a multiplicidade de práticas de leitura, a forma como são vivenciadas e aprendidas e os âmbitos sociais que funcionam como espaços estruturados, organizados por regras, com artefatos culturais disponíveis e acessados, modos de proceder, variando segundo as possibilidades de interaçóes. As exposiçóes a variados âmbitos sociais e as experiências que eles proporcionam aos seus participantes têm como decorrência a passagem por diversas comunidades de práticas (BARTON; HAMILTON; IVANIC, 2000). Tais comunidades não são apenas espaços a que somos expostos ou pelos quais passamos, são essencialmente sociais e constituídas por seus participantes. Nesses espaços são realizadas atividades, compartilhados sistemas de significação, que possibilitam atribuir sentidos ao próprio ato e às relaçóes que se estabelecem, nas quais se atribuem e ocupam determinados lugares. São contingenciais e podem ser provisórias, lóci onde se apreendem instrumentos culturais e se apropriam de objetos necessários à realização de tarefas, ao alcance de objetivos.

Os espaços e comunidades em que se pratica a leitura, em vários âmbitos e com objetivos os mais diversos, estabelecem relaçóes de interdependência com outros âmbitos e circunstâncias, apesar de guardarem as marcas institucionais que organizam os modos de praticar, os objetos legítimos e as formas de participação. Trata-se de mundos que convocam os sujeitos a tomarem parte em atividades, compartilharem significaçóes, ocuparem papéis e desempenharem-nos. Nesses espaços, "buscamos, construímos e mantemos as referências comunais de nossas identidades em 
movimento - lutando para nos juntarmos aos grupos igualmente móveis e velozes que procuramos, construímos e tentamos manter vivos por um momento, mas não por muito tempo." (BAUMAN, 2005, p. 32).

A perspectiva sócio-histórica e cultural convida a desvelar não somente as práticas de leitura locais e/ou dominantes, mas os sentidos e significados compartilhados na ação e as identidades leitoras produzidas nas/pelas interaçóes. O desafio consiste em perscrutar esses planos interdependentes e indissociáveis, buscando-se aceder tanto os discursos sobre a leitura que circulam e são apropriados e produzidos na/pela interação, como identificar e reconhecer as práticas de leituras, sejam as que se efetivam em condição de dominância e desigualmente distribuídas, sejam aquelas que se mostram funcionais para determinados grupos, sejam aquelas que possibilitam alterar situaçóes de desigualdade, nas quais se agenciam práticas dominantes para fins grupais e cotidianos, numa perspectiva emancipatória (SOUZA, 2009).

\section{Notas}

1 As ideias expostas neste artigo baseiam-se em tese de doutorado da autora (VÓVIO, 2007).

2 O trecho de entrevista analisado neste artigo faz parte do corpus de análise do doutorado da autora. Nesta pesquisa, foram focalizados os sentidos atribuídos à leitura, as trajetórias formativas e as práticas de leitura de um conjunto de educadoras de jovens e adultos de um programa comunitário localizado na região metropolitana de São Paulo, por meio de entrevistas semiestruturadas e grupos de conversa e discussão (VÒVIO, 2007).

3 Por vozes sociais, conceito fundante dos estudos da linguagem do Círculo de Bakhtin, compreende-se a rede de significaçóes sociais disponível e em (re)construção, a partir da qual se pode dizer e interpretar o mundo e a realidade. (BAKHTIN, 1981).

4 Conjunto de obras e textos consagrados e valorados socialmente por sua excelência no campo literário, considerados como patrimônio cultural e merecedores de conservação.

5 Consultar resultados da pesquisa Retratos da Leitura II, de iniciativa do Instituto Pró-livro, em 2008, disponível em: <http://www.prolivro. org.br/ipl/publier4.0/dados/anexos/1815.pdf>. 
6 Aprofundam esse debate os Estudos do Letramento, originados da distinção feita por Street $(1984,2004)$ entre letramento autônomo e ideológico, a identificação acerca dos mitos do letramento por Graff (1990) e as contribuiçóes de Heath (1989), de Barton, Hamilton e Ivanic (2000), de Gee (2000, 2004) e de Kleiman (1995, 2001a, 2002).

7 Ver, em Amorim (2008), os resultados da pesquisa Retratos da Leitura no Brasil, por exemplo.

8 Ver, por exemplo, as pesquisas desenvolvidas pelos integrantes do Grupo Letramento do Professor, no endereço <http://www.letramento.iel. unicamp.br/portal/?p=1608. Acesso em: 20 maio 2010 .

9 Tradução da autora. Na versão consultada, [...] la construcción de la literacidad está imbicada em las prácticas discursivas y en las relaciones de poder en la vida cotidiana: está socialmente construida, materialmente producida, moralmente regulada y tiene um significado simbólico que no puede reducirse a ninguno de estos.

\section{REFERÊNCIAS}

ABREU, M. Diferença e desigualdade: preconceitos em leitura. In: MARINHO, M. (Org.). Ler e navegar: espaços e percursos da leitura. Campinas: ALB/Ceale; Mercado de Letras, 2001. p. 139-157.

AMORIM, G. Retratos da leitura no Brasil. São Paulo: Instituto Pró-livro/ Imprensa Oficial do Estado, 2008. Disponível em: <http://www.prolivro. org.br/ipl/publier4.0/dados/anexos/1815.pdf> Acesso em: 5 maio 2010.

BAKHTIN, M. M. Marxismo e filosofia da linguagem. Sáo Paulo: Hucitec, 1981.

- Questóes de literatura e de estética: a teoria do romance. São Paulo: UNESP/ Hucitec, 1993.

BARTON, D.; HAMILTON, M.; IVANIC, R. Situated literacies: reading and writing in context. Londres: Routlege, 2000.

BAUMAN, Z. Identidade. Rio de Janeiro: Jorge Zahar, 2005. 
BOURDIEU, P.; CHARTIER, R. A leitura: uma prática cultural. In: CHARTIER, R. (Org.). Prática da leitura. São Paulo: Estação Liberdade, 1996. p. 229-253.

CERTEAU, M. de. A invenção do cotidiano: artes de fazer. Petrópolis: Vozes, 1994.

CHARTIER, R. Cultura escrita, literatura e história: conversas de Roger Chatier com Carlos Aguirre Anaya, Jesús Anaya Rosique, Daniel Goldin e Antonio Saborit. Porto Alegre: Artmed, 2001.

. Formas e sentido cultura escrita: entre distinção e apropriação.

Campinas: ALB/Mercado de Letras, 2003.

CUCHE, D. A noção de cultura nas Ciências Sociais. Bauru: EDUSC, 2002.

DIONÍSIO, M. de L. Literatura, leitura e escola: uma hipótese de trabalho para a construção do leitor cosmopolita. In: PAIVA, A. et al. (Org.). Leituras literárias: discursos transitivos. Belo Horizonte: Ceale/ Autêntica, 2005. p. 71-84.

DIONÍSIO, M. de L. A construção escolar de comunidades de leitores: leituras do manual de português. Coimbra: Almedina, 2000.

FLEURI, R. M. Intercultura e educação. Revista Brasileira de Educação, Sáo Paulo, n. 23, p. 16-35, maio/ago. 2003.

GALVÃO, A. M. de O.; BATISTA, A. (Org.). Leitura: práticas, impressos, letramentos. Belo Horizonte: Ceale/Autêntica, 1999.

GEE, J. P. The new literacy studies: from socially situated to the work of the social. In: BARTON, D.; HAMILTON, M.; IVANIC, R. Situated literacies: reading and writing in context. Londres: Routlege, 2000.

GEE, J. Oralidad y literacidad: del pensamiento salvage a ways with words. In: ZAVALA, V.; NIÑO-MURCIA, M.; AMES, P. (Org.). Escritura y sociedad: nuevas perspectivas teóricas y etnográficas. Lima: Red para el Desarollo de las Ciências Sociales en el Peru, 2004. p. 23-56.

GOODY, J. Language and writing. In: The interface between the written and the oral. Cambridge: Cambridge University Press, 1987. p. 258-259.

GRAFF, H. J. O mito do alfabetismo. Teoria \& Educação, Porto Alegre, n. 2, p. 31-63, 1990. 
HALL, S. A identidade cultural na pós-modernidade. Rio de Janeiro: DP\&A, 2003.

HEATH, S. B. Ways with words. New York: Cambridge University Press, 1989.

KALMAN, J. El estudio de la comunidad como un espacio para leer y escribir. Revista Brasileira de Educação, Rio de Janeiro, n. 26, p. 5-28, maio/ago. 2004.

KLEIMAN, A. B. (Org.). Os significados do letramento: uma nova perspectiva sobre a prática social da escrita. Campinas: Mercado das Letras, 1995.

A construção de identidades em sala de aula: um enfoque interacional. In: SIGNORINI, I. (Org.). Linguagem e identidade: elementos para uma discussão no campo aplicado. Campinas: Mercado de Letras; São Paulo: Fapesp, 1998. p. 115-138.

- Histórico da proposta de (auto)formação: confrontos e ajustes de perspectivas. In: KLEIMAN, A. B et al. O ensino e a formação do professor: alfabetização de jovens e adultos. Porto Alegre: Artmed, 2001a. p. 17-39.

Programas de educação de jovens e adultos e pesquisa acadêmica: a contribuição dos estudos do letramento. Educação e Pesquisa, São Paulo, v. 27, p. 267-281, jul./dez. 2001 b.

- O processo de aculturação pela escrita: o ensino da forma ou a aprendizagem da função. In: KLEIMAN, A. B. et al. O ensino e a formação do professor: alfabetização de jovens e adultos. Porto Alegre: Artmed, 2001c. p. 223-243.

A interface de questóes éticas e metodológicas na pesquisa em linguística aplicada. In: SILVA, D. E.; VIEIRA, J. A. (Org.). Análise do discurso: percursos teóricos e metodológicos. Brasília: UNB/Oficina Editorial do Instituto de Letras, 2002.

LAHIRE, B. Homem plural: os determinantes da ação. Petrópolis: Vozes, 2002.

LAHIRE, B. A cultura dos individuos. Porto Alegre: Artmed, 2006.

MOITA-LOPES, L. P. Identidades fragmentadas: a construção discursiva de raça, gênero e sexualidade em sala de aula. Campinas: Mercado de Letras, 2002. 
OLIVEIRA, M. K.; VÓVIO, C. L. Homogeneidade e heterogeneidade nas configuraçóes do alfabetismo. In: RIBEIRO, V. M. M. (Org.). Letramento no Brasil: reflexóes a partir do INAF. São Paulo: Global, 2003. p. $155-175$.

OLSON, D. R.; TORRANCE, N. Cultura escrita e oralidade. São Paulo: Ática, 1995.

OSAKABE, H. Poesia e indiferença. In: PAIVA, A. et al. (Org). Leituras literárias: discursos transitivos. Belo Horizonte: Ceale/Autêntica, 2005. p. 37-54.

RIBEIRO, V. M. M. Alfabetismo e atitudes: pesquisa junto a jovens e adultos. São Paulo: Ação Educativa; Campinas: Papirus, 1999.

RIBEIRO, V. M. M. (Org.). Letramento no Brasil: reflexóes a partir do INAF. São Paulo: Global, 2003.

SEMPRINI, A. Multiculturalismo. Bauru: EDUSC, 1999.

SITO, L. Ali tá a palavra deles: um estudo sobre práticas de letramento em uma comunidade quilombola do litoral do estado do Rio Grande do Sul. 2010. Dissertação (Mestrado em Linguística Aplicada) - Programa de Pós-Graduação em Linguística Aplicada, Instituto de Estudos da Linguagem, Universidade Estadual de Campinas, Campinas, 2010.

SOARES, M. B. Letramento: um tema em três gêneros. Belo Horizonte: Ceale/ Autêntica, 1998.

SOUZA, A. L. S. Letramentos de reexistência: culturas e identidades no movimento Hip Hop. Tese (Doutorado em Linguística Aplicada) - Programa de Pós-Graduação em Linguística Aplicada, Instituto de Estudos da Linguagem, Universidade Estadual de Campinas, Campinas, 2009.

STREET, B. Literacy in theory and practice. Cambridge: Cambridge University Press, 1984.

STREET, B. Los nuevos estudios de literacidad. In: ZAVALA, V.; MURCIA-NINO, M.; AMES, P. (Org.). Escritura y sociedad: nuevas perspectivas teóricas y etnográficas. Lima: Red para el Desarollo de las Ciencias Sociales em el Peru, 2004. p. 143-180. 
STROMQUIST, N. P. Convergência e divergência na conexão entre gênero e letramento: novos avanços. Educação e Pesquisa, São Paulo, v. 27, p. 301-319, jul./dez. 2001.

TARDELLI, G. Histórias de leitura de professores: a convivência entre diferentes cânones de leitura. Tese (Doutorado em Linguística Aplicada) - Programa de Pós-Graduação em Linguística Aplicada, Instituto de Estudos da Linguagem, Universidade Estadual de Campinas, Campinas, Universidade Estadual de Campinas, 2003.

VÓVIO, C. L. Entre discursos: sentidos, práticas e identidades leitoras de alfabetizadores de jovens e adultos. Tese (Doutorado em Linguística Aplicada) - Programa de Pós-Graduação em Linguística Aplicada, Instituto de Estudos da Linguagem, Universidade Estadual de Campinas, Campinas, 2007.

; DE GRANDE, P. B. O que dizem as educadoras sobre si: construçôes identitárias e formação docente. In: VÓVIO, C. L.; DE GRANDE, P. B., SITO, L. R. (Org.). Letramentos: rupturas, deslocamentos e repercussóes em Linguística Aplicada. Campinas: Mercado de Letras, 2010. p. 51-70.

ZAVALA, V. Quem está dizendo isso?: letramento acadêmico, identidade e poder na educação superior. In: VÓVIO, C. L.; DE GRANDE, P. B., SITO, L. R. (Org.) Letramentos: rupturas, deslocamentos e repercussões em Linguística Aplicada. Campinas: Mercado de Letras, 2010. p. 71-95. no prelo

ZAVALA, V.; NIÑO-MURCIA, M.; AMES, P. (Org.). Escritura y sociedad: nuevas perspectivas teóricas y etnográficas. Lima: Red para el Desarollo de las Ciencias Sociales en el Peru, 2004. 


\section{Discourses about reading: between unity and plurality}

\section{Abstract}

This paper discusses about approaches to reading that cross and constitute current discourses about this social practice and its meanings, therefore influential in the ways to focus attention on objects and in the analysis made in research on literacies (STREET, 1984; KLEIMAN, 1995; BARTON; HAMILTON; IVANIC 2000; GEE, $2000,2004)$. The adopted epistemology understands reading as a cultural practice produced in/by the relations between human groups at specific times and social spaces, making it variable. As such, it is influenced by phenomena that bring in their wake the necessity of reading as a desirable cultural practice: the legitimacy (of collective beliefs that constructed the reading as a necessary practice) and the inequality with respect to the distribution of opportunities, the diffusion of practices, competencies and objects (LAHIRE, 2002, 2006). Addressing these current discourses and the approaches relevant to them allows, on the one hand, to understand on what grounds the discourses of tradition and of the canon were produced and turned into watersheds capable of distinguishing groups and individuals, defining what counts, what has value, scaling and rating readers and readings and, on the other hand, to organize plans from which one can

\section{Discurso sobre la lectura: entre la unidad y la pluralidad}

\section{Resumen}

El presente artículo trata sobre los enfoques de la lectura que atraviesan y constituyen discursos corrientes sobre esa práctica social y sus significados, influenciando estos en los modos de cómo se focalizan los objetos y los análisis en las investigaciones sobre literacidades. (STREET, 1984; KLEIMAN, 1995; BARTON; HAMILTON; IVANIC 2000; GEE, 2000, 2004). La matriz epistemológica asumida comprende la lectura como práctica cultural producida en y por las relaciones entre grupos humanos, en tiempos y espacios sociales específicos, y de esta manera, variable. Así, esta práctica, está permeada por fenómenos que contienen en sí mismos la necesidad de la lectura como una práctica cultural deseable: de la legitimidad (creencias colectivas que edificaron la lectura como una práctica necesaria) y la desigualdad que implica la distribución de oportunidades de acceso, a la difusión de las prácticas, competencias y objetos (LAHIRE, 2002, 2006). Abordar estos discursos y sus enfoques correspondientes permite, por un lado, comprender en que bases el discurso de la tradición y de lo canónico fueron producidos y se convirtieron en divisiones de aguas capaces de distinguir grupos, y personas, de definir lo que cuenta, lo que tiene valor, de escalonar y clasificar lectores y lecturas, y, por otro 
examine the reading practices, the lado, organizar planos a partir de los meanings attributed to this doing and cuales se puede examinar la prácticas de the cultural artifacts accessed by the lecturas, los sentidos y los significados subjetcs involved.

Keywords: Literacy. Reading practices. Reader training. atribuidos a este hacer y a los artefactos culturales que los sujetos tienen acceso. Palabra clave: Literacidad. Prácticas de lectura. Formación lectora.

\section{Claudia Lemos Vóvio}

Universidade Federal de São Paulo - Escola de Filosofia, Letras e Ciências Humanas - Pedagogia. Estrada do Caminho Velho, 333, Bairro dos Pimentas Guarulhos, SP. CEP: 07252-312

Telefone: (11) 3381-2000 - Fax: (11) 2498-9768

E-mail: clvovio@uol.com.br

Recebido em: 1/7/2010 Aprovado em: 29/10/2010 